\title{
Employee Innovation in the Perspective of Differentiated Incentive Mechanism
}

\author{
Xin Zhu \\ School of Economics and Management \\ Guangxi University of Science and Technology \\ Liuzhou, China
}

\author{
Shiwen Liao* \\ School of Economics and Management \\ Guangxi University of Science and Technology \\ Liuzhou, China \\ 623273036@qq.com
}

\begin{abstract}
Innovation is the power and soul of enterprise development, and scientific and effective incentive mechanism is the "catalyst" of employee innovation. From the point of view of managers, technical $R \& D$ personnel, production personnel and sales personnel, this paper expounds the feasibility and importance of establishing the incentive mechanism of individual differentiation and departmental differentiation to employees' innovative behavior. Based on the relevant principles, this paper puts forward the reasonable countermeasures to construct the differential incentive mechanism, in order to provide a reference for the development of modern enterprises.
\end{abstract}

Keywords-differentiation; incentive mechanism; employee innovation; principles

\section{INTRODUCTION}

Simply understand the relationship between enterprises and employees as employment relations, employees as a tool for enterprises to make money, inhibit the enthusiasm and creativity of employees. According to the theory of motivation, proceed from the actual situation of the employee and the department, a different and diversified motivation model is set up, which can tap the innovative potential of the employee deeply and stimulate the innovative behavior of the employee effectively and improve the innovation ability of enterprises.

\section{Change THE INCENTIVE MECHANISM OF "No DISCRIMINATION, ONE SIZE FITS ALL"}

At present, most enterprises' incentive means is "one-sizefits-all". It is believed that one kind of incentive means is universal, and the same incentive means can be adopted for managers, technical R\&D personnel, production and sales personnel, the enterprise treat them "equally". This kind of rigid motivation approach ignores the need for employee differentiation, according to Maslow's hierarchy of needs, different people have different needs, in order to adapt to the environment and meet the diverse needs of employees, it is imperative to make motivation flexible to develop a differentiated incentive mechanism that varies from person to person and from department to department[1].

\section{PRINCIPLES TO BE FOLLOWED IN DifFERENTIAL INCENTIVE MECHANISM}

\section{A. Principle of differential motivation}

\section{1) Individual differentiation}

Employees'interest and sense of achievement in their work are the driving force for their innovative behavior. Everyone has different interests. Only by placing employees in the jobs that they love can they work on their own initiative. The sense of achievement that results from innovation will further motivate employees to innovate, creating a virtuous circle. There are also differences in gender, education and age. For example, female employees pay more attention to pay, while male employees pay more attention to career development; the employees with higher educational level pay more attention to spiritual motivation, while the employees with lower educational level pay more attention to material motivation; Younger workers are more likely to "job-hopping" and prefer challenging jobs, while older workers are more likely to want job security. Therefore, the establishment of a differentiated incentive mechanism will meet the needs of different individuals to fully mobilize their work enthusiasm and creativity.

\section{2) Sectoral differentiation}

The management department, which controls the lifeline of the enterprise's existence, shoulders the heavy responsibility of the enterprise's development, and faces the risk of decisionmaking mistakes. For managers, it is necessary to make a clear goal of technological innovation and increase the opportunity cost of innovation failure, and fully embody the harmonious unity of material and spiritual incentives, risks and benefits in the incentive model. Inspire managers to put forward creative ideas bravely, leading the enterprise pioneering and innovative. Setting up a scientific distribution system of innovation income can arouse managers'innovation enthusiasm and encourage them to pursue the maximization of innovation income[2].

The technology R\&D department, which is in charge of the $R \& D$ resources, carrying the enterprise's innovation dream and bearing the risk of $\mathrm{R} \& \mathrm{D}$ failure. For technology developers, most are highly educated, according to the Maslow's hierarchy of needs, a single physiological need is no longer sufficient. They want to upgrade their professional 
skills and knowledge systems through some kind of training to satisfy their higher need for respect and self-actualization[3]. In addition, providing R\&D personnel with sufficient $R \& D$ resources and a free working environment can create a soft environment with a strong innovation atmosphere and effectively stimulate their innovation behavior[4].

Sales department, holding the real-time demand of customers, providing customers with high-quality service, opening up the company's products market. For the sales staff, novel sales methods, creative sales thinking can effectively enhance their work performance. Some sales staff out of business for a long time, the sense of belonging is not strong, only to establish an excellent corporate culture, strengthen their care, attention to their needs, so that employees have a sense of belonging, happy to contribute to the enterprise. At the same time, can take a certain goal to encourage, and in the quarterly or annual target performance to give employees some incentives to enhance the enthusiasm and creativity of the sales staff.

The production department, which controls the enterprise production cost, implements the product production plan, is guarding against the inferior quality product appearance. For the production staff, they do the same work day after day, a sense of boredom arises, enthusiasm and creativity are under attack. Reasonable career planning will stimulate their enthusiasm for work, the enterprise can guide staff to technical work development according to their working conditions, and give them certain training and assessment, those who meet the requirements are given the opportunity to change jobs. At the same time, in the daily incentive, to reflect the principle of more work, according to Addams's equity theory, a fair and reasonable salary incentive can effectively stimulate the enthusiasm of production staff. In short, improving the internal and external reward level is the key to stimulate their work enthusiasm and motivation[5].

\section{B. Principles for the integrated use of multiple incentives}

At present, most enterprises have a single incentive method, and the incentive effect is not obvious, while the diversified incentive methods improve the flexibility of incentive, can meet more needs of employees, and can fully stimulate their intrinsic motivation.

\section{The principle of combining material encouragement with spiritual encouragement}

According to Maslow's hierarchy of needs, material incentives can meet people's physical and safety needs. And spiritual stimulation can satisfy people's higher needs, namely, the need for sociability, respect, and self-actualization. Both complement each other, the combination can meet the needs of employees at multiple levels. The two can also be transformed under certain conditions, for example, enterprises can mobilize the enthusiasm of employees through bonuses, that is, material into spirit; after employees are praised or cared for, it will motivate them to be more willing to contribute to the enterprise to bring more benefits to the enterprise, that is, spiritual into material. Therefore, material and spiritual incentives to take into account, can not be neglected.

\section{COUNTERMEASURES OF CONSTRUCTING A DIFFERENTIAL INCENTIVE MECHANISM}

\section{A. For Managers, paying attention to the Annual Salary} Incentive, Equity Incentive-based material incentive and Responsibility Incentive-based spiritual incentive

Annual Salary Incentive, which refers to the distribution system in which the enterprise determines and pays the salary of the operator according to the scale and performance of the Enterprise. It gives consideration to both fairness and efficiency, combines the interests of individuals and enterprises, and has the function of encouragement and restriction. The implementation of the incentive system is to managers to deal with high-risk, high creative ability affirmation, can fully stimulate their creativity, is conducive to the improvement of enterprise innovation.

Equity Incentive, which combines the self-interest of the managers with the long-term interest of the enterprise, in order to pursue the maximization of the wealth of the enterprise, the managers will improve the competitiveness of the enterprise through continuous innovation and provide conditions for the innovation activities of other departments, promoting technological innovation in enterprises. We should pay attention to the object of incentive, the condition of exercise right, the price of grant and the quantity when making the plan of Equity Incentive. If the incentive plan does not give full play to the incentive function, the senior managers will influence the company's Long-term development and reduce the $R \& D$ expenditure for their own benefit. We should reasonably set up the object of equity incentive, reduce the turnover rate of the company's core technical personnel, and make the enterprise obtain the greatest economic benefits. In the process of making and carrying out the plan, the enterprise should adjust the plan constantly. Every aspect of the equity incentive scheme will influence the effect of the equity incentive, and enterprises should make the equity incentive plan scientifically according to the market environment and their own characteristics, so as to improve the innovation performance of enterprises.

Responsibility Incentive, the innovation activity is a complex work, which needs many parties to undertake the responsibility together, to carry out the responsibility stimulation to the manager, the risk-sharing, is more advantageous to the manager to carry out its responsibility, feels fair, thus reduces the risk of the decision failure.

B. For the technical $R \& D$ personnel, paying attention to Working Conditions Incentive-based material incentive and Honor Incentive, Education and Training Incentivesbased spiritual incentive.

Working Conditions Incentive, enterprises provide a good working environment for technical $R \& D$ personnel, such as providing them with advanced research equipment, perfect laboratory, comprehensive information and research funds, and so on, to stimulate their creativity. At the same time, 
flexible working system can also better tap their innovative potential, improve the department's R\&D capacity.

Honor Incentive, to create a learning atmosphere to catch up with each other, to actively carry out innovation competitions, and to honor the employees, to meet their highlevel needs, to inject innovation into the enterprise vitality.

Education and Training Incentives, technical R\&D personnel need to constantly update their knowledge system, carry out planned education and training for them, provide opportunities for further study, help to improve the comprehensive ability of the staff, stimulate the innovative potential of the staff, creating a good environment to train talents and attract talents, fully reflects the "people-oriented" management philosophy. In addition to training employees on their current learning needs, the company should also develop a long-term training plan for them, which should be in line with the employees' career goals and their own development needs. So that employees can enjoy good long-term training and career development opportunities, employees and enterprises grow together, employees personal value will be fully reflected.

\section{For the sales personnel, paying attention to Salary \\ Incentive-based material incentive and Goal Incentive, Role Model Motivation-based spiritual incentive.}

Salary Incentive, as the most direct and effective way of the incentive means, uses the salary lever to arouse the staff's work enthusiasm. For high performing sales people, according to the Equity theory, a high salary level will give employees a sense of satisfaction and superiority[6], employees will recognize the value of their labor, feel the importance of their own business, enhance the competitive vitality of the enterprise.

Goal Incentive, by setting goals to stimulate the motivation of sales personnel, guide their behavior, so that sales personnel's personal goals and corporate goals are closely linked to inspiring the enthusiasm, initiative and creativity of sales personnel. An enterprise should formulate a medium-and long-term development plan, and conduct extensive and indepth publicity among sales personnel so that sales personnel can see the prospects and goals for the development of the enterprise. At the same time, an enterprise should involve sales personnel in the formulation of a medium-and long-term development plan and listen to them with an open mind. On the premise of understanding and accepting the development goals of the enterprise, sales staff will combine their personal career goals with the goals of the enterprise, mobilize their sales enthusiasm, better serve customers, and bring sales benefits to the department, bring profits to the enterprises, better for the enterprise to create value, for the enterprise advice, to meet the desire of employees to achieve self-value.

Role Model Motivation, role models around, role models set up a strong incentive function, such as "excellent salesman" , "Marketing Pacesetter" and other advanced figures to enable employees to catch up with the direction, stimulate creative sales thinking.

\section{For the production staff, paying attention to Career Incentive, Salary Incentive-based material incentive and Care Incentive-based spiritual incentive.}

Career Incentive, which lets the production staff see their career development prospects, according to the performance of employees, to give excellent employees the opportunity to promote, inspiring the enthusiasm of employees to strive to achieve self-worth.

Salary Incentive, on the one hand, it is the incentive of the creative motivation of the productive staff. According to Expectation theory, external motivation is the most intuitive judgment of the attraction of the results produced by the creative activities of the employees. It is through external compensation stimulation to promote the emergence of employee innovation demand. Enterprises should establish a perfect and targeted compensation incentive system, so that production personnel can clearly understand the specific benefits of this innovation, establish a good competition mechanism, and provide more adequate motivation for employees'innovation behavior; On the other hand, it is the incentive of the feedback of the innovation behavior and the innovation result of the production staff. When the individual innovation behavior of the staff can realize or obtain certain stage results, the enterprise should give the staff feedback and reward in time, such as bonuses or other forms of welfare.

Care Incentive, leaders care about the work and life of employees, through communication and encouragement, to establish a harmonious and friendly emotional relationship with employees, create a friendly cultural atmosphere, care for the suffering of employees, mobilize the enthusiasm of employees, enhance the sense of belonging.

\section{E. For individual employees, taking full account of individual} differences, implement differential incentives, pay attention to gender, age, education level differences.

Gender differences, for male employees, can be promoted to stimulate their work enthusiasm, for female employees, the allocation of their appropriate amount of work, to reduce their work pressure, or can be concerned about their physical problems, for example, by giving birth to paid leave to encourage female employees.

The age difference, for relatively frequent job-hopping young employees, according to their interests and expertise to allocate the appropriate work, to provide a good salary incentive employees, create a good working environment to retain employees. And for older employees to meet their higher-level needs is the key to motivating employees.

The difference of educational level, for the employees with higher educational level, match their professional knowledge to the proper position, and assign reasonable jobs according to their interests, while for the employees with lower educational level, focus on meeting their low-level needs, motivating employees by means of salary increase, etc.

\section{CONCLUSION}

Incentive mechanism and employee innovation are two eternal topics. How to stimulate employee innovation in 
incentive mechanism is the key to success. Only by keeping pace with the times, keeping a keen eye and a keen sense of smell, recognizing the diversity and scientificity of incentive mechanisms, constantly improving their deficiencies, and highlighting differentiation, can enterprises stand out in the fierce market competition to remain undefeated in today's world.

\section{REFERENCES}

[1] Tian Fujun, Li Zhaoyou. Motivation and mechanism design of flexible incentive for enterprise technological innovation [J]. Scientific and technological progress and countermeasures, 2014, 31(22):70-74. (In Chinese)

[2] Ou Yangxinnian. Motivation and interest incentive mechanism of enterprise technological innovation [J]. Scientific Management Research, 2004(03):21-25. (In Chinese)

[3] Liao Zhongju, Cheng Hua. A study on the influencing factors and performance of technological innovation incentive measures in enterprises[J].Research Management, 2014,35(07):60-66. (In Chinese)

[4] Wang Hui, Chang Yang. The influence of organizational innovation climate and work motivation on employee innovation behavior[J]. Management Science, 2017,30(03):51-62. (In Chinese)

[5] Zhao Feng, Liu Lixiang, Lian Yue. Research on incentive mechanism of innovative talents in the view of comprehensive incentive model[J]. Scientific Management Research, 2013,31(06):98-101. (In Chinese)

[6] Stephen P.Robbins. Organizational Behavior [M]. Beijing: Renmin University Press,2005. (In Chinese)

[7] Fu Jiaji. Technical Innovation [M]. Beijing: Tsinghua University Press, 1998. (In Chinese) 